\title{
Imágenes marcadas a fuego. Representación y memoria de la Shoah *
}

Vicente Sánchez Biosca

Universidade de Valência

\section{RESUMO}

Tomando como objeto de análise o documentário Shoah, este artigo estabelece relações entre imagem, representações, história e memória.

Palavras-chave: Shoah; cinema; memória.

\begin{abstract}
This article analyses the documentary Shoah, dealing with the relations between images/representation and history/memory.
\end{abstract}

Keywords: Shoah; cinema; memory.

El primer encuentro con el inventario fotográfico del horror extremo es una suerte de revelación, la revelación prototípicamente moderna: una epifania negativa. Para mí, fueron las fotografias de Bergen-Belsen y Dachau que encontré por casualidad en una librería de Santa Mónica en julio de 1945. Nada de lo que he visto — en fotografias o en la vida real - me afectó jamás de un modo tan agudo, profundo, instantáneo. En verdad, creo posible dividir mi vida en dos partes, antes de ver esas fotografias (yo tenía doce años) y después, aunque transcurrió mucho tiempo antes que comprendiera cabalmente de qué se trataba. ¿Qué se ganaba con verlas? Eran meras fotografias, y de un acontecimiento del que yo apenas tenía noticias y de ninguna manera podia remediar. Cuando miré esas fotografias, algo cedió. Se había alcanzado algún límite, y no solo el del horror: me senti irrevocablemente afligida, herida, pero parte de mis sentimientos empezaron a atiesarse; algo murió; algo llora todavia. ${ }^{1}$

Con su habitual fuerza y agudeza, Susan Sontag apuntaba con estas palabras, y en el corazón de su propia experiencia, los avatares, los límites, los riesgos y el porvenir de lo que se dio en llamar una 'pedagogia del horror'. Nuestros espíritus y nuestros ojos están, en plena era televisiva, demasiado acostumbrados a un consumo diario del horror. Quizá por ello nos resulte trabajoso operar un salto atrás en la conciencia y situarnos en el contexto de lo visible cincuenta

\footnotetext{
* Este artigo foi publicado no livro Segle XX: racionalitat, cultura i barbàrie, Gerona, Universidade de Gerona, 2000.
} 
anõs atrás, tal vez más trabajoso incluso que hacerlo a períodos más alejados en el tiempo, como por ejemplo a mediados del siglo XIX. Recordemos, pues, algunos hechos

El 12 de abril de 1945, todavia la rendición de Alemania no se habia producido. Sin embargo, tres notables artífices del Ejército norteamericano - George Patton, Omar Bradley y Dwight Eisenhower — visitan el campo de Ohrdruf, dependiente de Buchenwald. Sus ojos se estrellan contra un espectáculo que rebasa a todas luces una perspectiva militar y se resiste a entrar en los parámetros de lo hasta entonces concebido como un comportamiento de guerra. Este hecho y la decisión inmediata que toman dichos jerarcas de la Armada norteamericana constituyen un hito en la historia del encuentro entre los medios de comunicación y las Fuerzas Armadas. Y lo es porque la voluntad explícita de los gobiernos $y$, en particular, de las autoridades militares fue incidir en la vida civil, en la reeducación de los culpables y los cómplices, en el conocimiento de los testigos y de los que decián no saber. En efecto, los Aliados, especialmente los norteamericanos, atribuyeron dos funciones a la imagen indigesta de cuanto se veía en los campos: la muestra de los horrores como instrumento pedagógico y como forma de acusación. Testimonio y educación: pieza de convicción para un processo jurídico, mas igualmente confianza en que el sufrimiento de ojo ante lo inhumano debía ser garantía para evitar toda repetición. Si la pregunta que se hacían los soldados norteamericanos era "Why We Fight?", la respuesta — Eisenhower dixit estaba en estas imágenes y la brindaban los reporteros y documentalistas. Ante lo increible, lo innombrable, lo inefable, el ejército imponía un imperativo ético: ver a manos llenas.

Ahora bien, la pedagogia del horror implicaba también una educación de los culpables. ¿Como era posible que los alemanes no supieran? Los SS, mas también los apacibles ciudadanos de las problaciones cercanas (Weimar, por ejemplo, se hallaba junto a Buchenwald) fueron conducidos en una suerte de procesión punitiva o siniestro circuito turísitico a los lugares en que se exhibía un ceremonial del horror: cabezas reducidas, pieles humanas utilizadas como impíos objetos de decoración, órganos humanso conservados en formol. Una inmediata sintonia se produjo entre estas tentativas y la voluntad de muchos fotógrafos o cineastas independientes, como George Rodgers, Sydney Berstein o Lee Miller, pues éstos se esforzaron en planificar sus encuadres en profundidad de campo, procurando en todo caso mostrar sin corte alguno los visitantes y los cadáveres amontonados, con el fin de que sirviera de testimonio inequivoco. Ciertamenente, todo parecia increíble. Precisamente por ello era necesario levantar acta de su existencia para que nadie pudiera jamás negar su realidad. Levantar acta de de lo inverosímil exigía, lo sabían, una puesta en escena de la desnudez y una orientación hacia el trauma visual. 
A pesar de todo, las imágenes captadas, en cámara fotográfica o cinematográfica, no eran transparentes, no daban cuenta de los mismos hechos que los supervivientes calificaban de inefables. Por muy presto a dispararse que estuviera el objetivo, no había simultaneidad alguna entre los hechos vividos y los captados. Así, un primer rasgo discursivo se desprendía de la huida de lo real respecto a la mirada: su carácter metonímico. Los acontecimientos terribles eran revelados por imágenes no menos hirientes, pero éstas sólo mostraban sus resultados, no su processo. A ello se añade que los fotógrafos rara vez iban en la vanguardia del ejército, con lo que un retraso de cuatro o cinco días (es lo que le sucede por ejemplo a Rodgers al llegar a Bergen-Belsen) contribuía a deformar todavía más lo que el ojo del primer soldado contempló. Un extraño mito se forjaba en estos días al cual sólo la televisión del directo daría una también sorprendente respuesta: recuperar la mirada pura, el virginal encuentro con las cosas como si éste encerrara una verdad inextricable pero necesaria.

Quizá el mejor ejemplo contrario y también la prueba inequívoca de que toda estética de la reconstrucción espectacular o narrativa de los acontecimientos era imposible fue realizada por los cineastas soviéticos a la liberación de Auchwitz. Semanas después de este día, los mejores operadores ruedan una simulación de la liberación ante las alambradas a rebosar de prisioneros famélicos, pero con vendajes incomprensiblemente blancos. Várias cámaras recrean con cierto nervio la llegada de la vanguardia soviética, mientras la banda sonora reproduce vítores de júbilo de los recién liberados. A pesar de los cuerpos delgados de los deportados, unas vendas inverosimilmente blancas y pulcras desvelaban la farsa hasta tal punto que los soviéticos decidieron retirar la película de circulación. Los testimonios orales o escritos que evocan la llegada a Auschwitz del Ejército Rojo después de las marchas de la muerte que evacuaron el campo no dejan duda alguna respecto a la desolación que reinaba en el campo, el temor de los prisioneros a un regreso de los alemanes y cierta indiferencia de los militares hacia las victimas.

En cualquier caso, retornando a las imágenes norteamericanas y británicas, el imperativo ético (e incluso político e jurídico) que se exigia a los planos rodados había de determinar un tratamiento estético, imponer unos límites al ejercicio del montaje, mas también un modelo de filmación suficientemente probatorio. Así, el empleo de la profundidad de campo, apoyando el contraste entre personajes en primer plano y fondos de cadáveres, el recurso a la enunciación con sonido directo del día, la hora y la personalidad de los soldados ante cámara se concebian como índices ineludibles de realidad, pruebas irrefutables de la veracidad de aquello que se resistía a ser creído. Nada debía deteriorar el realismo hiriente de lo filmado: ver con dolor era sinónimo de aprender.

No en vano muchas de estas películas vinieron precedidas de declaracio- 
nes juradas de los responsables de efectos especiales fotográficos, testimoniando que ninguna operación de trucaje había sido emprendida y que, por demás, la copia presentada respondía integralmente al negativo original. Valga como ejemplo los dos textos que encabezan la película norteamericana producida por el United States Counsel of the Prosecution of Axis Criminality titulada Nazi Concentration Camps. El primero de ellos está firmado por Robert H. Jackson y reza así:

This is an official documentary report compiled from films made by military Photographers serving with the allied armies as they advanced into Germany. The films were made pursuant to an order issued by general Dwight D. Eisenhower, supreme commander allied expeditionary forces.

\section{Robert H. Jackson \\ United States \\ Chief of Counsel}

El segundo, firmado por George C. Stevens, en octubre de 1945, expresa que se trata de un documento oficial rodado por los fotógrafos que aconpañaban a las fuerzas armadas y que es fiel reflejo de la realidad y añade que el trabajo que se presenta fue encargado para $20^{\text {th }}$ Century-Fox, donde se ocupaba de los efectos especiales (fecha 25.08.1945). Certifica asimismo que este filme de 2.000 metros no ha sido modificado y representa el negativo original seleccionado entre los 25.000 metros de película similar en características que habían sido rodados. Este último documento aparece también al final del filme, demostrando una obsesión de autentificación, testificando de nuevo la veracidad de los hechos.

Mas no se trataba tan sólo de mostrar horrorizando, sino de denunciar y bien sabemos que la perspectiva común de las fuerzas aliadas fue distinguiéndose entre sí a partir de los años inmediatamente posteriores a la capitulación de Alemania, debido a los imperativos de la guerra fría y los cambios de estrategia que ésta implicaba. En consecuencia, las censuras, los aligeramientos de imágenes, fueron frecuentes y el reciclaje de material fue sufriendo diversos montajes siempre al servicio de los diversos y cambiantes contenidos políticos que se pretendía transmitir. Para ello se pusieron en funcionamiento voces en off de cuño propagandístico que incidian en tal o cual aspecto de lo concentracionario. Quizá lo más llamativo de todo ello, por su recurrencia, fue el oscurecimiento del exterminio judio en beneficio de una crítica a la deshumanización y cri- 
minalidad política de los nazis. Con este precario equilibrio circularon por los noticiarios de toda Europa y América durante los meses siguientes imágenes muy variadas, donde el remontaje era frecuente, aun cuando el requisito de verdad fue constante y consistía en no cortar ni montar en demasia. Algún día habria de realizarse un estudio pormenorizado de las fuentes, reescrituras, remontajes y aligeramientos que en los distintos países tuvieran estas imágenes. Pero no es éste mi cometido hoy.

Sin embargo, algo se olvida en toda esta estética; algo cuya dependencia de la ética y de la propaganda (y reténgase que se trata de dos cuestiones distintas y a menudo en contradicción) provoca una tensión fundamental en cuanto al efecto que reclama del espectador. Y esto es precisamente lo que Susan Sontag había detectado desde sus ojos de niña. Lo diremos en palabras de una superviviente: toute la pédagogie de l'horreur en reproduit la jouissance². Edificante o no, la imagen del horror es por definición una imagen del sinsentido y los cuerpos extremos, los cadáveres, los amasijos de huesos, las miradas ausentes de los musulmanes, no dejan, a pesar de la mejor voluntad, de desencadenar una extraña fascinación, un goce muy especial. Ya las vanguardias habían indagado en la idea de un ojo devorador y perverso, sediento de goce escópico, cuya mejor expresión eran los cuerpos despedazados y Georges Bataille levantó buen testimonio de ello en su Histoire de l'oeil ${ }^{3}$. A la pregunta que los sociólogos se hacen (¿hay acomodación al horror?; ¿se estimula con su reiterada representación una necesidad de incrementar sus dosis?), cabría añadir otra más interesante y de implicaciones más inciertas: ¿es compatible el goce del ojo con los principios éticos que se pretende transmitir?

Un punto de precario equilibrio, crucial para la historia de las representaciones cinematográficas de la violencia y la fascinación por los cuerpos despedazados ${ }^{4}$, puede encontrarse en una enigmática película firmada por Sydney Berstein cuyo título es Memory of Camps. A Painful Reminder, que contó con la intervención de Alfred Hitchcock en calidad de asesor de montaje. Su material de base no es otro que las filmaciones hechas por las fuerzas británicas al liberar Bergen-Belsen, acompañadas y aderezadas por otro metraje cedido por los americanos y fragmentos de Triumph des Willnes, de Leni Riefenstahl, entre otros. En ella se advierte un primer embrague de la fuerza escópica señalada y la voluntad ética y acusatoria en el seno de una endeble estructura narrativa que se pretendía remontarse al nazismo y a la guerra. Mas la precariedad estaba (y de paso el gran interés de su resultado) en la incapacidad que la película muestra para dulcificar el impacto de las imágenes de violencia y, además, en el anuncio de una relación traumática que toda discursivización ha de producir en las imágenes que le sirven de punto de partida 5 . 


\section{EL FILME DE MONTAJE: ANTE LA MEMORIA PERDIDA}

Una segunda estrategia documental se plantea una década más tarde. Se trata igualmente de una película, un mediometraje, cuyo impacto en la opinión pública, en la formación pedagógica y en la memoria colectiva, especialmente en Francia, iba a durar largo tiempo. A saber, Nuit et brouillard, realizada por Alain Resnais en 1955. La inmediatez delas imágenes y de su función interpretativa ya ha pasado, la reconstrucción de la mirada virginal del primer soldado que se dio de bruces ante el cuerpo objetualizado del superviviente no puede ya ser objetivo de la representación. Tampoco puede extrañar que tras una década numerosos instrumentos de discursivización (memorias, biografías, testimonios, escritura de la historia) se hayan hecho cargo de los acontecimientos reales. En pocas palabras, la historia amortaja los hechos y la actualidad que exige la mirada en riguroso presente da paso a una reflexión sobre el pasado que se articula necesariamente con el presente. Estamos, pues, ante un intento de inscribir una dialéctica comprometida: la historia y la memoria. Es así como Resnais, consiguiendo la colaboración del escritor Jean Cayrol, testigo directo de la experiencia concentracionaria por su estancia en Mauthausen, emprendió la realización de esta película.

En 1953-1954, había visto la luz un libro de gran relevancia para la memoria de la deportación. Se trata de Tragédie de la déportation 1940-1945. Témoignages des survivants des camps de concentration allemands, coordinado por Olga Wormser y Henri Michel, autores que se encontraban a la cabeza del comité d'Histoire de la Deuxième Guerre Mondiale, concretamente en un departamento llamado Commission d'Histoire de la Déportation. Ambos oficiaron de asesores históricos para el filme, por lo que Nuit et bruoillard ilustra un estado de la memoria y una propuesta de tratamiento del material documental de acuerdo con el estado de la reflexión histórica.

En su sentido estricto, la de Resnais es una película de montaje y asimismo un esfuerzo titánico por inscribir las huellas del pasado en el presente. En lugar de enterrar el pasado en el arropado territorio discursivo de la historia, Resnais vertebra su película sobre un marcado contraste entre lo que quedó de los campos (imágenes del presente que son filmadas en color) y la emergencia del pasado reproducido a través de fotografías en blanco y negro procedentes de múltiples archivos gráficos ${ }^{6}$.

Se desprende de ello la consciencia de dos exigencias: el testimonio es vital, la experiencia directa es la única legitimación para hablar de los hechos que amenazan la humanidad, mas el contacto directo no basta. La reflexión, el discurso se impone. El goce del ojo ya no puede éticamente dejarse correr, en un momento en que múltiples imágenes y relatos han sido construidos de modo obsceno sobre los detalles de lo vivido. Por su parte, el montaje no es sinónimo 
de falsificación, pues nadie duda de los hechos en sí, mas la huella precisa también ser resguardada y las fotos contienen ese presente inminente, aunque haga referencia a un pasado.

En efecto, el congelado que es norma de la fotografia es garante de un tiempo pasado pero real, captado para siempre e inmovilizado. Algo no puede ser transformado, algo resiste a la interpretación (las fotos, su fechación); algo, en cambio, debe ser recordado desde el presente y el montaje y la articulación del presente (verbal mediante el texto de Cayrol, visual mediante el uso del color) son los instrumentos de la misma. Una pregnancia ontológica del hecho, irrefutable, testigo (la fotografia) unida a un artilugio autorial, marcado, conductor de un discurso, como es por excelencia el montaje. Dos herramientas en contradictión?

Ahora bien, esta libertad mayor que se permite el realizador fruto de su exigencia ética hacia el presente y su rigor para con el ejercicio de la memoria entraña también un mayor margen de interpretación. Y el texto de vocación poética de Cayrol conforma la idea de un magno e igualitario universo concentracionario, uniforme, sin diferencias. David Rousset, en un célebre libro, bautizó así a este conjunto de circuitos de campos y en cierto modo Resnais lo certifica ${ }^{8}$. Hay modelos diferentes de campos en cuanto a su arquitectura y localización, pero la identidad de las víctimas, las condiciones de los campos son intercambiables y en este contexto el exterminio judio ocupa un lugar secundario y de complemento, es decir, subsumido a fin de cuentas en la inhumanidad del régimen nazi para con sus enemigos, políticos civiles o militares. Annette Wieviorka es terminante y de hecho no yerra al señalar a este respecto que el objeto de la película no es en ningún caso el exterminio judio".

Las imágenes tienen algo de ejemplaridad: son una ilustración. Y tal vez sea bien explícito en este sentido el título de la película, tomado del famoso decreto nazi Nacht und Nebel, en realidad consistente en tres textos diversos, el primero de los cuales data de 7 de diciembre de 1941, redactado por el mariscal de campo Keitel, pero explícitamente concebido por el mismo Hitler. Se trataba de establecer las lineas de comportamiento, en realidad sin precedentes, para con los enemigos del Reich y consistentes en que desaparecieran sin dejar rastro de la faz de la tierra, apoyándose en una frase de Alberich, personaje legendario de Das Rheingold, de Wagner, tan del gusto del Führer. Esta opción del título es, a fin de cuentas, reveladora de la primacía que se concebe a los prisioneros políticos en detrimento, en particular, del sórdido e irracional exterminio de los judíos. En este sentido, Nuit et brouillard responde a un tiempo y a unas creencias bien fechadas en la historia de la representación mental e historica de la Shoah y su concepción de la relación entre ética y estética es bien distinta de aquélla que advertíamos en Memory of Camps. 


\section{LUGARES MUDOS, TESTIGOS QUE HABLAN: SHOAH}

Shoah (Claude Lanzamann, 1985) es mucho más que una película, aun cuando sorprende hasta qué punto su estudio ha pasado por alto a los historiadores. Objeto de análisis para psicoanalistas, teóricos del cine, filósofos o pensadores en general, no ha despertado la necesidad de una investigación por parte de la disciplina histórica, a pesar de su enorme influencia en toda la comunidad judía internacional. Quizá no sea errado pensar que esta inmensa obra de nueve horas de duración ofrece una respuesta a la cuestión lacerante de Theodor Adorno sobre la legitimidad de crear una obra de arte después de Auschwitz, pues a fin de cuentas Shoah es también y sobre todo una obra de arte. Mas vayamos a lo que ahora nos interesa. Iniciada em 1974 y merecedora de once trabajosos años de sufrimientos, investigación, entrevistas y montaje, Shoah arranca de la constatación inevitable de que la memoria se ha convertido en tarea ardua y tal vez abocada al declive en los tiempos que corren, tanto debido a la avanzada edad de los supervivientes como a las esclerotización de una retórica que habla de manera cada vez más estandarizada del exterminio judío.

La película extrae toda su fuerza de una opción formal y ética insólita que la coloca en las antípodas de la elección del filme de montaje por Resnais, a saber: el rechazo de principio a toda imagen (fotografia, filmación) que recree un pasado perteneciente a los campos de la muerte, a saber, una imagen de archivo. Por el contrario, Lanzmann va en busca de los emplazamientos actuales en los que, contra toda verosimilitud, se perpetró la masacre del puebo judío. Visita los lugares en compañia de los protagonistas con el fin de provocar en ellos el surgimiento de la memoria. Ahora bien, no se trata de una memoria universal, pues no hay discurso colectivo capaz de hacerse cargo de lo vivido. Es el discurso de los sujetos lo que determina los acontecimientos y su recreación. Lanzmann, pues, se apresta a hacer nacer en ellos como si de un fantasma se tratara la imagen viva del pasado, mas dicha imagen jamás será exportable a los demás y, por consiguiente, nunca podrá materializarse más que como pesadilla transmitida por medio de la palabra.

Se trata aquí de una abolición de la distancia que separa del pasado, con lo que se propone alcanzar un atemporalidad que corresponde más al trauma y el inconsciente mismo que a un universo discursivizado, relatado, historiable. Si existen imágenes documentales en el filme de Lanzmann, éstas nacen del encuentro entre los lugares del pasado tal y como han permanecido y la palabra de los supervivientes. Había que rendirse a una evidencia: aquello que los soldados británicos y norteamericanos habían observado con sus ojos aterrorizados ya no existe. Por ello, lo que hay al comienzo del film — dice Lanzmann es, por una parte, la desaparición de las heullas; no hay ya nada, sino la nada y a 
partir de ella había que hacer un filme. Por otra parte, existía la imposibilidad de contar por parte de los supervivientes, de parir la cosa, lo innombrable ${ }^{10}$. En consecuencia, el silencio es la primera diana a la que apunta el realizador, el silencio no del pasado, sino del presente. Las arrugas en los rostros, el malestar de las personas entrevistadas, la desfiguración del marco espacial de estos "no-lugares de la memoria”, como dice Lanzmann invirtiendo la conocida expresión de Pierre Nora: la entrada a Auschwitz, el río Ner en los alrededores de Chelmno, la vía del ferrocarril que conduce de Malkinia a Treblinka, los crematorios... todo permanece mudo y desierto.

En suma, es la belleza sosa de los paisajes y la indiferencia de un tiempo privado de nexos con el pasado, lo que deve ser interrogado: "Yo era consciente del cambio y al mismo tiempo me era necesario pensar que el tiempo no había hecho su trabajo" ${ }^{\prime 1}$. Lo anodino es, pues, la condición de los lugares ante los cuales Lanzmann pone en marcha una batería implacable destinada a asediar a los supervivientes, verdugos y testigos, hasta hacer aparecer ante ellos los fantasmas del pasado. Función reveladora de la palabra, nada en realidad es posible sin ella ni puede darse por existente. Y así, la palabra, la oralidad, adquieren la misión más relevante en Shoah, pues a través de ellas se atraviesa el tiempo, se inscribe lo vivido para desaparecer definitivamente.

Lanzmann confesó que las primeras entrevistas con los supervivientes y testigos eran de una total confusión, por lo que se vio obligado a transformar a los personajes en actores de su próprio drama para obtener los primeros resultados. Mas los transformaba precisamente en los actores de unos papeles que éstos habían efectivamente desempeñado en el pasado. Ésta es exactamente la paradojica dramaturgia de Lanzmann. Así, la fuerza dramática contenida en estas entrevistas contrasta con el ideal de neutralidad que advertimos en otro tipo de testimonios grabados en vídeo que se han puesto en marcha en las últimas décadas, como el proyecto emprendido por Spielberg o por la Universidad de Yale, a los que aludiremos más adelante. Además, Shoah se encuentra dotada de una estructura matemáticamente calculada y el montaje, pese a respetar la oralidad del testimonio, es de una precisión infernal.

Consideremos a modo de ejemplo el relato por uno de los personajes que mayor presencia adquieren en Shoah, a saber, Filip Müller, tal y como aparece en sus memorias tituladas Sonderbehandlung (Tratamiento especial) ${ }^{12}$ : la riqueza inagotable de la experiencia contrasta con una falta de potencia de palabra que, en cambio, rebosa en la película de Lanzmann. Su voz de narrador, su mirada alucinada, sus ojos perdidos a medida que se hunde en el pasado, sus largos silencios y su dicción pausada recuerdan esa figura del narrador oral típico de antaño de cuya ausencia y pérdida tanto lamentó Walter Benjamin en un texto que trata de la pérdida del valor de la experiencia y su transmisión por vía 
narrativa. Sólo con una excepción: el relato de Müller no versa sobre un tiempo vivido, como el relato del marinero y del campesino evocados por Benjamin, sino que su tema es el más sórdido de los imaginables, pues trata del contacto diario, monótono e inacabable con cadáveres.

$\mathrm{Y}$, con todo, Müller construye un tableau vivant más que un relato alterando sus tiempos verbales al presente repentinamente, su hermosa voz que marca la cadencia de una visión. Además, su narración no avanza linealmente como las leyendas, sino que la palabra busca un sostén en el espacio, se torna flotante, apuntando al acontecimiento originario. Lanzmann traza con pudor un recorrido con su cámara por los espacios descritos, como si un ojo penetrara lentamente por el espacio desierto, sin más huella aquella que las palabras inscriben en la ausencia.

A continuación, me centraré en tres fragmentos cuyo tema es el campo de Treblinka. En el escenario en que antaño estuvo este campo reina ahora una desolación todavía mayor que en Auschwitz-Birkenau, convertido en monumento a la memoria. Dicho de otra manera, Treblinka no posee la riqueza metafórica que bien se puede atribuir a Auchwitz: monumentalidad, hipérbole de la masacre mecanizada, conglomerado de las funciones de campo de trabajo, instalación de las industrias alemanas, campo de concentración y de exterminio, todo al mismo

292 tiempo. Las dimensiones más modestas de Treblinka, espacial y cuantitativamente, riman bien con la monotonia de su objetivo: la muerte.

Recurriré a los ejemplos de tres personajes cuyas funciones coinciden con los tres registros de la experiencia de la Shoah que fueron descritos por el historiador Raul Hilberg, a saber: ejecutores, víctimas y testigos ${ }^{13}$. Sólo el representante de la tercera categoría será transportado por Lanzmann a los lugares de la tragedia. Pese a todo, la cámara realizará también en el resto de los casos el siniestro trayecto compasada por la palabra. El lugar en que se efectúa la entrevista con el ejecutor Suchomel es familiar, una habitación de su domicilio en la que el anciano y enfermo Unterscharführer se conplace en ofrecer la 'voz de la Historia' a su interlocutor, pese a su modesta renuncia a firmar su testimonio y la condición impuesta a su interlocutor de preservar su anonimato. En segundo lugar, la víctima Abraham Bomba toma la palabra en una peluquería de Holon (Israel), espacio dotado de siniestras semejanzas con aquél de Treblinka en el que antaño ejerció su trabajo. Por último, Henrik Gawtawski, empleado polaco de ferrocarriles, es el testigo mudo por excelencia que emplea largo tiempo antes de poder despegar los labios $\mathrm{y}$ articular las primeras palabras.

EL GOCE DEL EJECUTOR

Franz Suchomel, Unterscharführer SS destinado en Treblinka entre septiem- 
bre de 1942 y noviembre de 1943, había comparecido como acusado ante la corte de Düsseldorf en 1963, por la que fue condenado a seis años de trabajos forzados por su participación en el asesinato de 300.000 detenidos. En el filme de Lanzmann, el entrevistador le tiende una celada en la que cae: lo lleva a revivir el pasado a través de una serie de preguntas técnicas que rehuyen cualquier valoración moral. El lenguaje administrativo, cuantitativo, estadístico y descriptivo en el que Suchomel enuncia su discurso no es otro (y Lanzmann bien lo sabe) que el deshumanizado y cosificado discurso del III Reich. De ahí que su frialdad burocrática concierte plenamente con el desempeño de sus funciones de antaño y, al propio tiempo, reproduzca de manera sintomática el lenguaje administrativo del régimen al que obedecía. Por supuesto, esta actitud por parte del entrevistador implica una momentánea suspensión del juicio, pero hace infinitamente más impresionante la emergencia de un lenguaje venido del pasado inscrito a fuego en cada palabra fría, neutra, del entrevistado en contradicción con el tema dramático del que éste trata, el asesinato en masa. He aquí el objetivo de Lanzmann: despertar en el anciano de hoy su lenguaje de antaño, hacerle representar por medio de las palabras algo de su personalidad del pasado, mas como si se tratara del mesmísimo presente.

Es aquí donde Suchomel cede al orgullo de su condición de 'historiador' de una historia vivida, testigo ejemplar y acaso único de ciertos hechos que ningún otro, cree él, podría referir con tanta autenticidad y legitimidad. Su discurso no lo carga el odio a los judíos, más bien diríamos que es la indiferencia la que habla por su boca y ésta es en realidad tanto más insoportable a nuestros oídos. Así pues, decidido a dar a su entrevistador esa pieza única de convicción que es, en su propios términos, 'Historia en estado puro', entona un canto que hace irrumpir el pasado en el interior de esta modesta estancia:

\author{
Mirada al mundo de frente \\ siempre bravos y alegres, \\ marchan los comandos marchan al trabajo. \\ Para nosotros hoy nada hay más que Treblinka, \\ que es nuestro destino. \\ Hemos asimilado Treblinka en un abrir y cerrar de ojos. \\ Sólo conocemos la palabra del comandante \\ y sólo la obediencia y el deber. \\ Deseamos servir, y servir todavía más \\ hasta que la pequeña felicidad un dia \\ nos llame.j Hurra!
}

En efecto, si no la Historia en estado puro, sí hay algo aquí que se presenta 
sin contaminaciones, ni distancias. Todo aparece inscrito en la imagen pobre de un cuerpo que quiere proteger su anonimato, borrándose modestamente como sujeto. El terror nace de esa voz desgastada con la que pronuncia un inmenso himno a la muerte. Tras esta anatomía en decadencia, advinamos el cuerpo robusto del joven Suchomel, repleto de proyectos para su futuro militar como SS. Basta leer la canción literalmente para convencerse. Nadie dejaría de ver surgir por un instante los cuerpos de los deportados que caminaban también derechos a la muerte para convertirse en materia prima. Es a esos cuerpos desaparecidos a los que Suchomel presta su voz, ya que era esta letanía la que debían aprender los comandos especiales a su llegada a Treblinka e interpretar con convicción al cabo del mismo día ante la orgullosa mirada de sus verdugos y los de su pueblo.

El acto narcisista de Schomel produce un efecto, pues, insospechado: en lugar de borrar su presencia como sujeto que rehusa la publicidad, un relámpago mágico lo transporta al pasado ante nuestros ojos y lo muestra en su esplendor, en su más pleno narcisismo destructor. Sus dificultades articulatorias, su condición de anciano enfermo, son paradójicamente la más rotunda prueba de su poderío de antaño y de la pervivencia de aquellos deseos, sea o no consciente su artífice. Suchomel ignora que en esa imagen, captada de forma clandestina por la cámara, en medio de ese decorado miserable ambientado por un croquis del campo de Treblinka, ofrece su goce para nuestro horror. Es esto lo que resulta obsceno, insoportable. Suchomel, a fin de cuentas, ha regresado al lugar del crimen para recuperar su juventud a través de esta canción siniestra. De este modo, perpetra una vez más el asesinato, lo autentifica, con una fuerza sin límites hasta reventar la pantalla.

Todo queda maravillosamente expresado en un breve intercambio de palabras que sigue la explosión del goce, cuando el cuerpo del verdugo se relaja y recupera la sórdida realidad que lo envuelve en la actualidad. Lanzmann aprovecha sutilmente la ocasión para intervenir con emponzoñada suavidad e incrustar de paso su actitud ética hacia el ejecutor:

Suchomel: Sí. Ahora reímos y, sin embrago, ¡es tan triste! Lanzmann Nadie ríe.

La entrevista prosigue con un método que es enunciado por Raul Hilberg en un fragmento de la película y que fue el mismo procedimiento de indagación que utilizó el historiador en su larga investigación sobre la Shoah: "Nunca comencé por las grandes cuestiones, pues temía débiles respuestas. Escogi, por el contario, dedicarme a las precisiones y los detalles con el fin de organizarlos en una Gestalt"

El hecho merece ser subrayado: Lanzmann se encuentra frente a un buró- 
crata del III Reich, no frente a un criminal convencional, ni siquiera frente a un criminal a secas. Dicho estatuto incierto había sido el arguemnto de su defensa ante el tribunal que lo juzgó y, por tanto, se hacía necesario interrogarlo en su propio lenguaje 0 , más exactamente en el lenguaje que, interiorizado como estaba, Suchomel compartía con el régimen al que servía. Las preguntas son claras y precisas: "Llega un convoy. Me gustaría que describiese exactamente todo el proceso durante el período de máximo rendimiento del campo". El entrevistador no muestra ningún reparo a recurrir a los mismos eufemismos que definieron el lenguaje de los SS: número de personas 'tratadas', color de los uniformes; en suma, un cúmulo de detalles técnicos de apariencia insignificante. Situar el momento preciso y su proceso en cadena: llegada, selección, espera, rapado, duchas, tratamiento, limpieza, comienzo de una nueva operación. Lo que se impone a la mirada y al espíritu del espectador es el abismo insondable entre la minuciosidad de los datos técnicos y la dimensión metafísica del crimen al que se alude. La imagen escueta de la habitación se opone al croquis que en la pared del fondo representa el campo de Treblinka. La estación, la rampa, la cámara de gas, el crematorio. La cámara de Lanzmann se desprende de este lugar para recorrer los verdaderos lugares de Treblinka tal y como subsisten en el presente. Entretanto, Suchomel se vacía en pormenores. La belleza de una puesta de sol nos alivia momentáneamente de la angustia del Mal absoluto.

\section{UN DOLOR QUE NO EDIFICA}

Abraham Bomba es un superviviente de Treblinka que fue deportado desde la ciudad de Czestochowa. Su oficio de barbero le salvó la vida al llegar al campo ya que fue empleado por las SS para cortar el cabello de las mujeres justo antes de su gaseamiento. Bomba es entrevistado por Lanzmann en Israel mientras corta los cabellos de un cliente en una barbería (en realidad, Bomba ya no ejercía este oficio desde hacía tiempo y se trata de una escenificación que contribuye a insertalo en su papel del pasado). Lejos del lugar de la tragedia, sin anclajes materiales, Lanzmann se ve forzado a trabajar con la similitud de las situaciones con el fin de arrancar la palabra. A pesar de todo, el entrevistado mantiene un discurso distante respecto a su objeto, haciendo gala de una frialdad descriptiva sorprendente. Cierto que los hechos que narra no carecen de dramatismo, mas la pasión y los afectos del sujeto se mantienen controlados, sin duda por el paso del tiempo. El dolor parece así ajeno a la palabra y ésta discurre con fluidez, sin llegar - claro está - a la ligereza.

En Treblinka - relata Bomba - él y sus compañeros, los barberos del comando especial, esperaban a las mujeres en el interior de las cámaras de gas con 
el fin de ahorrar tiempo a la operación de preparación y gaseamiento. De idéntico modo a como había procedido con Suchomel, Lanzmann dirige sus preguntas hacia los detalles minúsculos, casi ridículos en comparación con la dimensión de los hechos: con qué instrumentos cortaban los cabellos de las víctimas, cuál era la velocidad de sus movimientos, cuánto tiempo se prolongaba cada operación, cuál la longitud de los cabellos, en qué consistía el decorado (espejos, sillas, etc). Reconstruir las coordenadas espaciotemporales parece, de este modo, fundamental para componer una Gestalt o imagen de conjunto. En ningún momento está en juego la apelación directa, la pregunta por los sentimientos e el juicio moral del testigo. Lo singular se impone entonces desde el único punto de vista que interesa: el hombre en ese entorno, en ese lugar, en ese tiempo. Y es aquí donde empieza a abrirse paso la dimensión no domesticada de la experiencia y, con ella, inevitablemente surgirán los afectos.

El interrogante clave es por fin enunciado: ¿qué sintió usted la primera vez? Esta apunta a lo originario, pues Lanzmann está firmemente convencido de que todo lo que sigue la primera vez es mecánico, serial, impensado e incluso insentido. La primera vez es lo impensable, el momento, mítico, en que la maquinaria se pone en marcha. El entrevistador revela aquí sus ideas previas, sus fantasmas personales y no lo esconde en lo más mínimo. Es más, con el fin de sumergir al personaje en su papel del pasado, le ruega que imite los movimientos de antaño con sus tijeras. El rostro, como el discurso de Bomba, permanece pese a todo inalterable, como sí el acontecimiento hubiera sido preservado por una distancia infranqueable que lo protegiese de toda emergencia del afecto. La cámara explora su gesto y, al cabo de cierto tiempo, el peso del silencio resquebraja los asideros del presente y la certeza del discurso se perfora. Los ojos de Bomba se impregnan de lágrimas, su voz se rompe y el anciano suplica a su entrevistador y en cierto modo torturador, le ahorre este inútil sufrimiento. Lanzmann se muestra cruel y dulce a un mismo tiempo, implacable en suma: "Sabe que es necesario. Sé que es duro. Perdóneme”. Es entonces cuando Abraham expulsa los hechos que había intentado extirpar de su vida y de su recuerdo.

Un día, uno de sus camaradas vio entrar en la cámara de gaz a su esposa y su hermana para cortarse los cabellos antes de desaparecer para siempre en cenizas. Momento de una extrema intensidad en el que el esposo y hermano, sin poder despegar los labios ni advertir a sus seres amados de la muerte inminente que les esperaba, prolongó algunos segundos, un minuto quizá este breve, último y mudo encuentro, retardando la operación, desgarrado de dolor. Relatando un hecho que pertenece a la historia personal de otro y del que Bomba fue testigo, un foso se abre en su discurso para engullirlo, soltando las amarras temporales para transportarlo a ese lugar imposible en el que "las cosas se dan a la vista en una suerte de alucinante intemporalidad o, mejor, atemporalidad" ${ }^{14}$. Es- 
ta realidad que surge como una alucinación parece muy cerca de aquella concepción que Jacques Lacan formuló, a saber: lo real concebido como lo imposible.

\section{EL SILENCIO DEL TESTIGO}

Un último testigo, una nueva estrategia de discurso, un mismo lugar. Otra vez Treblinka. El personaje es el polaco Henrik Gawtawski, cuyo oficio consistió en conducir los trenes con transportes especiales entre la estación de Malkinia, en el nudo ferrorviario polaco, y Treblinka, campo de la muerte. El sujeto había ralizado mecánicamente su trabajo en multitud de ocasiones durante el periodo álgido de funcionamiento del campo. Ahora lo vemos a bordo de una locomotora, envejecido, asomado a la ventana. Escruta el paisaje con un gesto pensativo, casí idiotizado, en total silencio, sólo roto por el ruido de la máquina. Diríase que no reconoce nada del paisaje. De repente, el ferrocarril se detiene sin que pueda saberse la razón. Cuando el cuerpo del maquinista se yergue, un panel sobresale del bello paisaje de la verdura, como un bajorrelieve. Su mero nombre nos hace estremecernos: TREBLINKA. Ni una sola palabra. Aquí Shoah parece situarse en las antípodas de la oralidad. El viejo maquinista gira la cabeza hacia toda una serie de vagones inexistentes, ya que el ferrocarril está en realidad compuesto tan sólo por la locomotora. En un estado cercano al éxtasis, lleva mecánicamente su mano a la garganta y hace un gesto terrorífico de degollamiento, que repite por dos veces.

Irrupción repentina del pasado que ha sido lograda merced a la intervención de un reconocimiento del escenario que hace al personaje franquear el umbral del pasado y saltar por encima de las constricciones del tiempo: la atemporalidad surge entonces como el tiempo del trauma, es decir, como una falta absoluta de tiempo. Es como si el destino de las víctimas hubiera surgido ante sus ojos. Lanzmann confiesa haberse quedado helado por este gesto inesperado, pese a haber alquilado él mismo la locomotora y haber invitado al maquinista a efectuar por última vez ese trayecto: "Llegamos a la estación y se le ve ahí, asomado y, por sí mismo, hace ese gesto increíble en su garganta mientras mira los vagones imaginarios (...). Comparadas con esta imagen, las fotos de archivo se hacen insoportables. Esta imagen es la verdad misma" ${ }^{\prime 15}$. 


\section{MisTERIOS DE LA PUESTA EN ESCENA}

El proyecto de grabación de testimonios de supervivientes de la Shoah emprendido en las últimas décadas por varias instituciones, entre las que destaca por su magnitud y la multiplicidad de centros delegados el denominado Survivors of the Shoah. Visual History Foundation, auspiciado y puesto en marcha por Steven Spielberg de resultas de los contactos por él efectuados durante el rodaje en Cracovia de su film de ficción Schindler's List, en 1992, nos ofrece un modelo postrero de tratamiento del testimonio. Asimismo, nos permitirá una comparación con el tratamiento escénico, artístico y memorístico que acabamos de analizar, in extenso, de Claude Lanzmann. En el proyecto de Spielberg, los rasgos de la puesta en escena apuntan idealmente a un grado cero de escritura que borraría por completo, o tanto como ello fuera posible, la intervención del entrevistador, la presencia misma de la cámara, la variación entre duración de planos o tomas. Después de enunciar el lugar, la fecha, la lengua en que se efectúa la entrevista y la identidad del entrevistador, así como del superviviente, el tratamiento en continuidad de cada cinta de video, tan sólo matizado en ocasiones por un ligero zoom o reencuadre, sin vocación enfática, la ausencia de mirada a cámara y la exclusión del entrevistador del campo visual, expresan la voluntad de huir de cualquier dramatización del relato por procedimientos otros que la voz del testigo y los elementos visuales pragmáticos que le van unidos (sus silencios, sus gestos, sus explosiones de emoción, caso de que éstas se produzcan). En ningún caso le es lícito al entrevistador romper el silencio, colmar las lagunas o preguntar más de lo estrictamente necesario.

La duración usual de las entrevistas Survivors of the Shoah ${ }^{16}$ oscila entre cuatro y ocho cintas de video de 30' de duración cada una de ellas (así pues, entre 2 y 4 horas), siempre dependiendo de la voluntad o predisposición al relato de cada superviviente. Al término de los relatos, el entrevistado suele presentar algún miembro se su familia si lo considera oportuno y comentar fotos de familia, pertenecientes a sus antepasados, muchos de elllos fallecidos o asesinados en los campos de concentración. El objetivo consiste en la reconstrucción de la familia, dado que ésta ha sido destruida en gran proporción. En suma, se trata de un ejercicio de enraizamiento en la tradición familiar, quebrada por la barbarie.

Ahora bien, las marcas de enunciación no pueden extirparse por completo en la organización de las entrevistas. Así, aunque de gran flexibilidade, éstas siguen un orden cronológico: arrancan evocando los orígenes familiares, la infancia, haciendo hincapié en la percepción de elementos antisemitas en el periodo anterior a las leyes antijudías, su relación con los no judíos; a continuación, la detención, el reagrupamiento en campos franceses y, por fin, la deportación al 
Este $^{17}$; para concluir, el retorno y la reintegración en la vida social, civil, familiar tras la guerra. En la actualidad, me encuentro empeñado en realizar un estudio algo más sistemático de algunos rasgos retóricos, narrativos y compositivos de estas entrevistas, mas su desarollo en este texto desbordaría con mucho los objetivos que hoy me guian.

Este tipo de proyectos que se han generalizado en los últimos veinte años responde, por una parte, a una reacción frente al crecimiento del negacionismo; pero también nacen al calor del auge de la memoria y la moda incluso de la historia oral de la parte de los modernos historiadores, que obedece a una revisión de la relación entre lo público y lo privado, lo singular y lo colectivo en la historia. En efecto, dar nombre a todos los supervivientes, como a los muertos, es un magno y loable esfuerzo humanitario por invertir el asesinato en masa emprendido por los nazis: gentes sin nombre y con sólo número, gaseados masivamente retoman su identidad humana, aunque sea tras la muerte.

Ahora bien, también la singularidad, el relato individual, tiene sus riesgos: en primer lugar, reduce la información, la experiencia a la de las víctimas, dejando de lado aquellas dos figuras tan ricas para la documentación sobre la Shoah que Hilbert y Lanzmann habían incluido en sus investigaciones, a saber: los testigos y los ejecutores. Esto obliga a definir la noción de superviviente o a presuponerla. Además, supone integrar la preeminencia de lo individual en el registro de lo informático, de la estadística, pues para el estudio se aplica una serie de criterios generalizables cuya vertebración con lo singular debe ser adecuadamente pensada.

Por último, parece especialmente relevante señalar el reto que esta magnífica y desbordante información, repleta necesariamente de errores, faltas de perspectiva e impostaciones procedentes de la tradición concentracionaria, plantea a los historiadores. Éstos en efecto deben estudiarla, pero también filtrarla y contrastarla. Todo exceso de fiabilidad, toda sacralización de la memoria en detrimento de la historia llevaría a fabricar, como dijo Annette Wieviorka en una ocasión una documentación repleta de errores que, mal juzgados, podría llegar a ser de oro para los negacionistas ${ }^{18}$.

\section{EL PORQUÉ, EL MITO, EL CONTRAMITO, LA ESCATOLOGIA}

Mas regresemos por última vez a Shoah, objeto privilegiado de estas páginas por su desmesura. A la película de Lanzmann se le ha reprochado en alguna ocasión haber hecho revivir el horror mas que ayudar a comprenderlo. Es ésta la opinión de Tzvetan Todorov en su espléndida obra Face à l'extrême ${ }^{19}$. Lanzmann, sin embargo, es pese a todo firme en su planteamiento: "Dirigir sobre el 
horror una mirada frontal exige que renunciemos a las distraciones y escapatorias, la primera de la cuales y la más falsamente central, es la cuestion del porqué" ${ }^{20}$. Y añade: "Un filme dedicado al Holocausto no puede ser más que un contramito, es decir, una investigación sobre el presente del holocausto o, cuanto menos, sobre un pasado en el que las cicatrizes están tan frescas y vivamente inscritas en los lugares y las conciencias que se dan a ver en una alucinante intemporalidad"21.

Las ideas que expresan las citas anteriores pueden ponerse en relación entre sí: faltando el porqué, la causa, sólo el mito (¿el contramito?) estaría en condiciones de servirnos en la empresa. Avancemos por este delicado derrotero, pues es la transmisión misma lo que hace surgir el acontecimiento originario, en la medida en que abole toda distancia entre el pasado y el presente. En consecuencia, el pasado aparecería como un acontecimiento originario. Desde este punto de vista, Shoah tiene algo de mítico, ya que los humanos no disponemos de otro instrumento para remontarnos a los orígenes primeros. Así, el esfuerzo por arrancar los hechos de la experiencia llamándola 'la verdad', como hace Lanzmann, en su sentido metafísico, no puede ser la obra ni el trabajo del historiador. Sólo los orígenes y el porvenir escapan al ejercicio de la historia: unos cayendo bajo el reinado del mito; el otro, de la futurologia o la escatologia. La radicalidad de Shoah consiste en desvelar el lado escatológico de la Shoah al tiempo que funda un mito. Que el mito sea real, en su sentido más fuerte, es decir, como imposible, no reduce en absoluto el valor de la investigación; antes bien, lo acrecienta.

\title{
EL PRIMER JUDÍO Y EL ÚLTIMO
}

Para conservar en la memoria, desearía evocar las palabras con las que arranca Shoah:

\author{
Una casita blanca \\ Permanece en mi memoria. \\ Con esta casita blanca \\ Sueño cada noche.
}

En el lugar en el que se escucha esta cancionilla tuvo lugar el acontecimiento originario, lo imposible, objeto único de Shoah, a saber: la Endlösung o solución final: el gaseamiento en camiones de los primeros judíos junto con prisioneros de guerra soviéticos en diciembre de 1941.

Otras palabras se deján oír alrededor de nueve horas más tarde, justo antes de la irrupción de un sórdido rumor de ferrocarril, fin de un film sin esperanza: 
Y recuerdo un momento

En que sentí una especie de alivio,

De serenidad,

Y me dije:

soy el último judío,

voy a esperar la mañana,

voy a esperar a los alemanes.

La mañana siguiente al apocalipsis, ésas son las palabras de uno de los supervivientes de la insurrección del gueto de Varsovia, justo cuando esperaba no serlo. Con ellas se cierra el filme. Este es el testigo para el porvenir. Dos lugares derruidos, dos personajes que nos hablan de él: Simon Srebnik nos ofrece el contracanto de Franz Suchomel, la más radical inversión de un estallido de goce. Ninguna abolición del tiempo percibo aquí, diga lo que diga Lanzmann. El último nos habla desde el día siguiente a la tragedia, desde este amanecer de duelo y plomo que resulta todavía más inextricable que la masacre misma.

\section{NOTAS}

${ }^{1}$ SONTAG, Susan. Sobre la fotografia. Barcelona: Edhasa, 1981, pp. 29-30.

${ }^{2}$ STERN, Anne-Lise, cit. Por Liliane Kandel ("La lettre volée de Danile J. Goldhagern ou Un 'réviosionnisme radical”. Les Temps Modernes, no 592, febrero-marzo, 1997, p. 49.

${ }^{3}$ BATAILLE, Georges. Histoire de l'oeil. Paris: Jean-Jacques Pauvert, 1967.

${ }^{4}$ La expresión remite, claro está, a Jacques Lacan en cuanto este autor señala un cuerpo unificado en el espejo a través de la identificación imaginaria. Frente a ella, el cuerpo que percibe, en lo real, sería este cuerpo despedazado, informe.

${ }^{5}$ Véase nuestro estudio “Hier ist kein Warum. A propos de la mémorie et de l'image des camps de la mort”, Protée, 25-1 (1997), pp. 53-65.

${ }^{6}$ Un estudio minucioso de esta película señalando la procedencia de cada uno de los planos puede encontrarse en Richard Ruskin: Nuit et bruoillard by Alain Resnais. On the Making, Reception and Functions of a Major Documentary Film, Aarhus University Press, 1987. Un estudio textual que contextualiza los usos discursivos de la película en el conocimiento histórico y estético de los testimonios de la deportación puede encontrarse en la tesis de licenciatura inédita de Arturo Lozano Aguilar, Nuit et bruoillard: entre la historia y la memoria, Universidad de Valencia, Dpto. Teoría de los Lenguajes, bajo la dirección de Vicente Sánchez-Biosca, curso académico 1997-1998.

${ }^{7}$ Vienen a nuestra memoria las palabras de Roland Barthes: "Lo que la Fotografia reproduce al infinito únicamente há tenido lugar una sola vez: la Fotografia repite mecánicamente lo que nunca más podrá repetirse existencialmente" (La cámara lúcida. Nota sobre la Fotografia, Barcelona, Gustavo Gili, 1982, p. 31.). 
${ }^{8}$ ROUSSET, David. L'univers concentrationnaire. Paris: Minuit, 1965 (texto de 1945).

${ }^{9}$ WIEVIORKA, Annette. Déportation et génocide. Entre la mémoire et l'oubli. Paris: Plon, 1992.

10 "Le lieu et la parole", entrevista com Claude Lanzmann en Au sujet de Shoah. Paris, Berlín, 1990, p. 295.

11 “Les non-lieux dela mémoire', en Au sujet de Shoah, ya cit., p. 290.

${ }^{12}$ Trois ans dans une chambre à gaz. Paris, Pygmalion/Gérard Watelet, 1980 (original alemán de 1979).

${ }^{13}$ HILBERG, Raul. Victims, Bystanders. The Jewish Catastrophe 1933-1945. Nueva York, HarperCollins, 1992.

14 "Les non-lieus de la mémoire", Au sujet de Shoah, ya citado, p. 285.

15 “De l'Holocauste à Holocauste ou comment s'en débarrasser". Au sujet de Shoah, ya citado, p. 300.

${ }^{16}$ Agradecemos la gran amabilidad con que fuimos acogidos en París por el Centre de Documentation Juive Contemporaine (CDJC), en cuyos archivos pudimos consultar numerosos testimonios videográficos pertenecientes a la sección francesa de dicho proyecto de investigación.

${ }^{17}$ Las consultas que he realizado en el CDJC conciernen tan sólo a los deportados al Este, pero existen en los archivos otros casos distintos.

${ }^{18}$ Annete Wieviorka en el “Colloque de Cerisy”, Cinéma/Telévision et Histoire, julio de 1997.

${ }^{19}$ TODOROV, Tzevevan. Face à l'extrême. Paris, Seuil, 1991, p. 292.

302 20 “Hier ist kein Warum", ya citado, p. 279.

${ }^{21}$ LANZMANN, Claude. "De l'Holocauste à Holocauste ou comment s'en débarrasser”, en Au sujet de Shoah, ya citado, p. 316 . 